Ferreira, RS. (2020). Biodigesters and the factors that determine their maximum production. Research, Society and Development, 9(7):1-10. e544972677.

\title{
Biodigestores e os fatores que determinam sua máxima produção
}

Biodigesters and the factors that determine their maximum production

\section{Los biodigestores y los factores que determinan su producción máxima}

Recebido: 27/01/2020 | Revisado: 11/02/2020 | Aceito: 18/05/2020 | Publicado: 26/05/2020

\section{Ramon de Souza Ferreira}

ORCID: http://orcid.org/0000-0002-1629-1741

Universidade Federal dos Vales do Jequitinhonha e Mucuri, Brasil

E-mail: marromsf@hotmail.com

\section{Resumo}

Os biodigestores têm sido estudados e melhorados de forma acelerada nessa última década. A preocupação em alterar a matriz energética mundial dando prioridade às formas de energia limpa e deixando de lado o uso de combustíveis fósseis coloca a utilização de biogás para geração de energia como sendo uma alternativa atrativa. Além de ser uma forma de energia limpa, ainda é capaz de evitar que compostos prejudiciais ao ecossistema como metano, gás carbônico e gás sulfídrico sejam lançados na atmosfera. $\mathrm{O}$ objetivo da presente pesquisa é apresentar um levantamento bibliográfico atualizado sobre a tecnologia utilizada nos biodigestores e os fatores que influenciam diretamente na produção do biogás. Após a análise bibliográfica, foi possível identificar que através da leitura correta, análise e controle do $\mathrm{pH}$, temperatura, tempo de retenção hidráulica, quantidade de nutrientes e água no sistema e do processo de agitação da matéria orgânica dentro do reator é possível se obter uma maior quantidade de biogás inclusive de melhor qualidade. O que determina a qualidade do biogás é a quantidade de gás metano na composição, pois é o metano que será aproveitado para a queima.

Palavras-chave: Biodigestores; Energia limpa; Biogás.

\footnotetext{
Abstract

Biodigesters have been studied and improved in an accelerated way in the last decade. The concern to change the world energy matrix, giving priority to the forms of clean energy and leaving aside the use of fossil fuels, puts the use of biogas for energy generation as an
} 
attractive alternative. In addition to being a form of clean energy, it is also able to prevent compounds harmful to the ecosystem such as methane, carbon dioxide and hydrogen sulphide from being released into the atmosphere. The objective of that research is to present an updated bibliographic survey on the technology used in biodigesters and the factors that directly influence the production of biogas. After the bibliographic analysis, it was possible to identify that through the correct reading, analysis and control of $\mathrm{pH}$, temperature, hydraulic retention time, amount of nutrients and water in the system and the organic matter agitation process inside the reactor it is possible to obtain a greater amount of biogas, including better quality. What determines the quality of the biogas is the amount of methane gas in the composition, as it is the methane that will be used for burning.

Keywords: Biodigesters; Clean energy; Biogas.

\section{Resumen}

Los biodigestores han sido estudiados y mejorados de manera acelerada en la última década. La preocupación por cambiar la matriz energética mundial, dando prioridad a las formas de energía limpia y dejando de lado el uso de combustibles fósiles, coloca el uso de biogás para la generación de energía como una alternativa atractiva. Además de ser una forma de energía limpia, también es capaz de evitar que los compuestos nocivos para el ecosistema como el metano, el dióxido de carbono y el sulfuro de hidrógeno se liberen a la atmósfera. Este trabajo realiza una encuesta bibliográfica actualizada sobre la tecnología utilizada en biodigestores y los factores que influyen directamente en la producción de biogás. Después del análisis bibliográfico, fue posible identificar que a través de la lectura, el análisis y el control correctos del pH, la temperatura, el tiempo de retención hidráulica, la cantidad de nutrientes y agua en el sistema y el proceso de agitación de la materia orgánica dentro del reactor, es posible obtener un mayor cantidad de biogás, incluida mejor calidad. Lo que determina la calidad del biogás es la cantidad de gas metano en la composición, ya que es el metano que se utilizará para la combustión.

Palabras clave: Biodigestores; Energía limpia; Biogás.

\section{Introdução}

Um biodigestor consiste em uma câmara fechada que propicia às bactérias anaeróbias, o ambiente perfeito para digerir matéria orgânica e em consequência desse processo gerar 
biogás. Esses biodigestores podem funcionar por batelada, isso é, trabalhando uma carga de cada vez ou com fluxo contínuo onde a mesma quantidade de dejetos que entram são os que saem, sendo armazenada apenas enquanto é decomposta internamente. Os principais modelos de biodigestor são os indianos, chineses e canadenses.

O biogás é um gás composto em sua maioria por metano e pequenas porções de gás carbônico e gás sulfídrico, dentre outros, em menores quantidades ainda. Segundo Kostaneski (2018), o biogás é composto principalmente por metano que representa entre 50 e $70 \%$, gás carbônico entre 25 e 45\%, gás sulfídrico entre 0,005 e 2\% além de H2, N2, CO e O2.

De todos os gases gerados coexistentes no biogás, o que pode ser utilizado é o metano. Para isso é necessário que se faça a purificação do composto utilizando-se óxido férrico que elimina o gás sulfídrico (Oliveira, 2009). O mais comum feito em pequena escala é a utilização de esponja de aço. Para a retirada do gás carbônico é feita a lavagem do composto com água. Essa etapa é feita injetando esse gás em um recipiente contendo água.

Após ser feita a purificação o biogás já está pronto para ser utilizado. $\mathrm{O}$ mesmo pode ser queimado para a geração de energia térmica ou também pode ser queimado para geração de energia elétrica. Essa definição dependerá do projeto em que o biodigestor estará inserido.

Entretanto, os biodigestores precisam contar com certas características e fatores para que possam produzir de forma eficiente. De acordo com o que foi desenvolvido até então, os principais fatores determinantes na máxima produção de biogás são o controle de potencial Hidrogeniônico $(\mathrm{pH})$, temperatura, tempo de retenção da matéria orgânica no sistema, quantidade de água no sistema, quantidade de nutrientes e agitação.

Para que ocorra a produção de biogás é necessário que sejam observados todos os fatores que contribuem e são capazes de estabelecer um ambiente propício para que as bactérias responsáveis pela geração possam atuar de forma mais eficiente possível.

Atentar para as técnicas de geração de biogás é essencial, pois, mesmo atingindo patamares altos de biogás, ainda assim é fundamental que esse biogás contenha em sua composição altos níveis de gás metano, pois esse é o gás aproveitado do composto. O objetivo desse trabalho e identificar todos os fatores que são responsáveis pela geração do biogás nos biodigestores.

Metodológicamente se realizam um levantamento bibliográfico atualizado e a anáslise respectiva sobre a tecnologia utilizada nos biodigestores e os fatores que influenciam diretamente na produção do biogás. 


\section{Potencial Hidrogeniônico (pH)}

Para a máxima produção de biogás de qualidade, isto é, biogás com a maior quantidade de metano em sua composição, afinal é o metano que será aproveitado de todo esse processo é necessário controlar o $\mathrm{pH}$ dentro do biodigestor. Para o melhor aproveitamento é recomendável que o pH fique entre 6,6 e 7,4 (Sakuma, 2013). Caso ocorra desses valores estarem abaixo de 6 ou acima de 8 , a produção cairá de forma considerável e a qualidade do biogás também será afetada.

Não é de se estranhar se não ocorrer também a produção de biogás. Caso ocorra produção, possivelmente esse gás não apresentará condições necessárias para sua queima. Será um gás composto principalmente por gás carbônico sendo que esse não é inflamável.

Quando ocorre algum problema no $\mathrm{pH}$ interno de um biodigestor, é mais comum que este esteja ácido. Caso seja um biodigestor de pequenas proporções e que sua finalidade seja apenas doméstica ou do tipo, é possível adicionar cal hidratada - hidróxido de cálcio $\mathrm{Ca}(\mathrm{OH}) 2$ - para que o $\mathrm{pH}$ seja equilibrado novamente e a composição do biogás possa ser normalizada de forma que o mesmo possa ser aproveitado.

\section{Temperatura}

Com relação à temperatura, as bactérias anaeróbias conseguem se desenvolver de forma mais acelerada e eficiente entre $25^{\circ} \mathrm{C}$ e $35^{\circ} \mathrm{C}$ (Chernicharo, 1997; Kostaneski, 2018). Caso ocorra alguma mudança drástica na temperatura interna do biodigestor, a produção de biogás é afetada diminuindo significativamente.

Se a temperatura atingir marcas menores que $15^{\circ} \mathrm{C}$, a biodigestão será mais demorada e em consequência terá baixa produção de biogás (Barrera, 2003). Esse problema assola algumas regiões, por exemplo, do Brasil, principalmente no sul do país onde as temperaturas em determinadas épocas podem cair de forma drástica.

Como solução para contornar esse problema, uma parte do próprio gás gerado pode ser queimado para gerar calor e aumentar a temperatura interna. Sendo o biodigestor de pequeno porte, parte do gás também pode ser queimado, com o objetivo de aquecer água que pode ser inserida no sistema aumentando também a temperatura interna do biodigestor.

Já para o aumento de temperatura, caso atinja mais que $35^{\circ} \mathrm{C}$, e no Brasil não são muitas essas regiões, as mudanças são na quantidade de biogás produzido. 


\section{Tempo de Retenção da Matéria Orgânica no Sistema}

O tempo de retenção da matéria orgânica dentro do sistema ou mais comumente conhecido como tempo de detenção hidráulica é o tempo necessário que a matéria orgânica deve permanecer dentro do biodigestor para que o processo de degradação da matéria ocorra e a produção de biogás atinja seu ápice. Para a geração de biogás e tratamento da matéria orgânica, o tempo de detenção hidráulica ideal fica entre 30 e 40 dias (Lustosa, 2014).

Quando o biodigestor vai ser construído primeiramente deve-se realizar o estudo do dimensionamento. Esse dimensionamento é realizado de acordo com a carga diária que será inserida no sistema e o não dimensionamento acarreta em problemas tanto de excesso como de falta de matéria orgânica.

Caso a quantidade inserida seja menor que o ideal, o sistema trabalhará de forma ineficiente produzindo menores quantidades de gás e devido à capacidade do biodigestor 0 tempo de detenção hidráulica será maior visto que não haverá quantidade suficiente de material para atingir a saída do biodigestor e ser expelida.

Sendo a quantidade de material inserido maior que o suportado pelo biodigestor, as bactérias não terão tempo suficiente para degradar a matéria orgânica. Acontecendo isso, o processo não chega a ser finalizado acarretando em menor produção de biogás e gerando um material pastoso que ainda não pode ser usado como biofertilizante além de exalar mau cheiro (Alves, 2007).

Porém, para simplificar o cálculo de dimensionamento de biodigestores existem tabelas que podem e devem ser consultadas para a construção do projeto como apresentada na Figura 1. Essa relação faz a associação entre a capacidade do biodigestor e a alimentação diária seguindo os tempos de retenção hidráulica de 30 e 45 dias respectivamente.

Figura 1 - Relação entre tamanho do biodigestor e limites diários de alimentação

\begin{tabular}{ccc}
\hline $\begin{array}{c}\text { Biodigestor } \\
\left(\mathbf{m}^{\mathbf{3}}\right)\end{array}$ & $\begin{array}{c}\text { Alimentação diária } \\
(\mathbf{T R}=\mathbf{3 0} \text { dias }) \mathbf{m}^{\mathbf{3}}\end{array}$ & $\begin{array}{c}\text { Alimentação diária } \\
(\mathbf{T R}=\mathbf{4 5} \text { dias }) \mathbf{m}^{\mathbf{3}}\end{array}$ \\
\hline 10 & 0,3 & 0,25 \\
20 & 0,6 & 0,5 \\
50 & 1,6 & 1,25 \\
100 & 3,2 & 2,5 \\
300 & 9,6 & 7,5 \\
500 & 16,6 & 12,5 \\
1000 & 30 & 25 \\
\hline
\end{tabular}

Fonte: Alves, 2007. 
Essa relação é bem simples e independe de conhecimento sofisticado e avançado. Entretanto, é extremamente importante que essas recomendações sejam cumpridas com o objetivo de alcançar a máxima produção de biogás.

\section{Quantidade de Água no Sistema}

Em se tratando da quantidade de água dentro do sistema, existem estudos que indicam uma proporção ideal de água em relação à quantidade de matéria orgânica. Isso também depende da origem dessa matéria.

Caso ocorra a alta concentração de água, é necessário adicionar mais matéria orgânica até atingir a proporção ideal. Da mesma forma se ocorrer de haver muita matéria orgânica em relação à água presente.

Dessa forma, Alves (2007) defende que a concentração de sólidos dentro da mistura entre água e matéria orgânica esteja entre 5 e $6 \%$ e que seja adicionada mais água ou não dependendo da umidade inicial do sistema. O sistema deverá funcionar seguindo as misturas indicadas pela Figura 2.

Figura 2 - Relação entre origem e quantidade de resíduos e água adicionada ao sistema.

\begin{tabular}{lccc}
\hline Dejetos & Quantidade (kg) & Água (litros) & $\begin{array}{c}\text { Proporção na } \\
\text { prática }\end{array}$ \\
\hline Bovinos & 150 & 190 & $01: 01$ \\
Suínos & 110 & 220 & $01: 02$ \\
Aves & 80 & 240 & $01: 03$ \\
Caprinos & 70 & 260 & $01: 03$ \\
Búfalo & 150 & 190 & $01: 01$ \\
\hline
\end{tabular}

Fonte: Ibid, 2007.

Para a classe dos suínos, caso haja criação em confinamento, é necessário observar que o sistema poderá estar recebendo também como contribuição líquida a urina dos suínos e a água proveniente da lavagem das baias. Nesse caso é necessário ter uma atenção especial para a quantidade exagerada de água no sistema. 


\section{Quantidade de Nutrientes}

Mesmo que se consiga regular os fatores citados, anteriormente neste artigo, uma vez que todos podem ser resolvidos de forma bem dinâmica, ainda existe outro fator que é um pouco mais complexo de se resolver, mas que se constitui em um grande problema. Para que o processo tenha sucesso e produza grande quantidade de biogás com alta concentração de metano é necessário que a matéria orgânica contenha uma boa quantidade de nutrientes.

A matéria orgânica mesmo sendo proveniente de um mesmo tipo de animal ainda é bastante variável. Por exemplo, os dejetos suínos de uma região podem ser totalmente diferentes dos dejetos suínos de outra região. Esses dejetos se caracterizam exclusivamente pelo tipo de alimento consumido pelos suínos e pela saúde desses animais.

Para que ocorra a produção de metano, as bactérias metanogênicas que são responsáveis por essa produção precisam de alguns nutrientes específicos. Os principais são Carbono, Nitrogênio, Fósforo e Potássio. As proporções são de 20:1 a 30:1 entre Carbono e Nitrogênio e de 1,9 g/L de potássio, 3,1 g/L de nitrogênio, 2,3 g/L de fósforo (Kothari et al., 2014; Estevez et al., 2012).

\section{Agitação}

Quando os dejetos são inseridos em um biodigestor, bactérias anaeróbias começam formar colônias para que possam degradar essa matéria orgânica. Essas colônias estarão situadas onde houver mais nutrientes e por esse motivo serão distribuídas de forma disforme.

Outra coisa que ocorre no interior do biodigestor é a formação de biogás. Esse biogás vai sendo formado e continua em sua posição original podendo estar dentro da massa de matéria orgânica. A condição ideal é que esse biogás seja desprendido e que saia logo que formado para o uso. Entretanto, não é isso que ocorre: por esse motivo, é necessário que o operador faça uma agitação interna no biodigestor. Essa agitação será capaz de quebrar as colônias formando outras novas e possibilitando que as bactérias estejam presentes em toda matéria inserida.

Por meio da agitação também é possível desprender todo o biogás que se encontra dentro do biodigestor, podendo estar ele dentro da matéria ou no fundo do reservatório. Esse procedimento pode ser feito tanto manualmente em caso de biodigestores pequenos ou por 
motobombas sendo para os biodigestores maiores. É recomendado que esse procedimento seja feito uma vez por semana por um tempo aproximado de 15 minutos (Alves, 2007).

\section{Considerações Finais}

Os biodigestores podem desempenhar um papel fundamental na diversificação da matriz energética mundial. É necessário que novas fontes de energia limpa sejam desenvolvidas, aprimoradas e disponibilizadas para a população.

Essa tecnologia é capaz de tratar de três temas principais. Em primeiro lugar, é possível aproveitar o biogás proveniente da fermentação e quebra da matéria orgânica para a geração de energia. Quando essa matéria orgânica é quebrada, gases que outrora seriam disponibilizados na atmosfera de forma descontrolada passam a ser aproveitados e tratados pelos biodigestores. Um exemplo é a não emissão de dióxido de carbono.

Outra vantagem da utilização desses equipamentos é a produção de subprodutos. Após os dejetos serem decompostos pelas bactérias, essa matéria que será descartada é extremamente rica em nutrientes utilizados como fertilizantes. Desta forma, temos outra fonte de recursos, o biofertilizante, o qual pode ser amplamente utilizado.

Por último, e mais visado temos a produção de biogás. Ele é o ator principal nesse processo. É pelo biogás que os biodigestores estão sendo disseminados pelo mundo, mas, todos os outros benefícios também devem ser levados em conta. Porém, tona-se necessário que os sistemas sejam aprimorados de forma que possam operar da maneira mais eficiente possível e tendo esses fatores de influência de máxima produção com pré-requisitos para o sucesso do desenvolvimento e utilização dessa tecnologia.

Por meio do controle de todos os fatores que influenciam na produção de biogás, é possível garantir que a produção ocorra em máxima escala e garantindo altos níveis de gás metano no biogás.

Caso algum desses fatores abordados neste estudo, não seja observado, é possível que não ocorra produção de biogás. Se por algum motivo ainda assim algum biogás for gerado, provavelmente ele terá baixas concentrações ou nenhuma de metano, ocasionando em desperdício de tempo e matéria prima além de ter um material não degradado e mal cheiroso como subproduto. 


\section{Referências}

Alves, RGCM. (2007). Tratamento e valorização de dejetos da suinocultura através de processos anaeróbios - operação e avaliação de diversos reatores em escala real. 2007. Tese (Pós-Graduação em Engenharia Ambiental) - Universidade Federal de Santa Catarina, Florianópolis.

Barrera, P. (1983). Biodigestores: Energia, fertilidade e saneamento para zona rural. São Paulo:Ícone.

Chernicharo, CAL. (1997). Princípios do tratamento biológico de águas residuárias: reatores anaeróbios. Belo Horizonte: Segrac, V.5, P. 245.

Estevez MM, Linjordet R \& Morke, J. (2012). Effects of steam explosion and co-digestion in the methane production from salix by mesophilic batch assays. Bioresource technology, 104: 749-56.

Kostaneski, PCM. (2018). Comparação da eficiência de lagoas de estabilização e biodigestores no manejo e tratamento de dejetos em empreendimentos da suinocultura no município de Toledo - PR. Universidade Estadual do Oeste do Paraná, março.

Kothari R, Pandey AK, Kumar S, Tyagi VV \& Tyagi SK. (2014). Different aspects of dry anaerobic digestion for bio-energy: an overview. Renewable and sustainable energy reviews, 39: $174-195$.

Lustosa GN \& Medeiros IHB. (2014). Proposta de um biodigestor anaeróbio modificado para produção de biogás e biofertilizante a partir de resíduos sólidos orgânicos. Monografia de Projeto Final, Departamento de Engenharia Civil e Ambiental, Universidade de Brasília, Brasília, DF, 72P.

Oliveira RD. (2009). Geração de energia elétrica a partir do biogás produzido pela fermentação anaeróbia de dejetos em abatedouro e as possibilidades no mercado de carbono. Trabalho de Conclusão de Curso. Engenharia Elétrica. Escola de Engenharia de São Carlos. São Carlos. 
Sakuma AC. (2013). Desenvolvimento e análise experimental de biodigestores modulares de baixo tempo de residência. Dissertação (mestrado) - Universidade Federal do Paraná, Setor de Tecnologia, Programa de Pós-graduação em Engenharia. Curitiba.

Porcentagem de contribuição de cada autor no manuscrito Ramon de Souza Ferreira - 100\% 